\title{
Information Technology in Italy: The Origins and the Early Years (1954 - 1965)
}

\author{
Corrado Bonfanti \\ Associazione Italiana per l'Informatica ed il Calcolo Automatico (AICA), Italy \\ corradobonfanti@hotmail.com
}

\begin{abstract}
Narration will be mainly focused on the origin, course and aftermath of four far-reaching initiatives that bloomed in Italy at almost the same time, in a few months encompassing 1954 and 1955; a choice which implies unfair omission of other worthwhile but less influential happenings.
\end{abstract}

Keywords: Italian computers, information technology, computer relics.

\section{Introduction: 'Make' or 'Buy'}

Until 1954, few Italian mathematicians and engineers - no more than a dozen - enjoyed the opportunity of some insight and acquaintance with stored-program electronic computers, on the occasion of study missions at the most renowned pioneering installations in England and especially in the United States; but none of such technological marvels was still running in Italy.

Two different approaches - 'make' or 'buy' - were viable to fill the gap and both were actually pursued ${ }^{1}$.

\section{The 'buy' Approach}

- The Polytechnic University of Milano acquired, in USA, a CRC 102-A computer to equip the just then set up Centro di Calcoli Numerici. The machine was running by October 1954 and the Centre officially opened some months later.

- The Consiglio Nazionale delle Ricerche (CNR) bought in England a Ferranti Mark I* for the Istituto Nazionale per le Applicazioni del Calcolo (INAC). The FINAC (Ferranti-INAC) machine arrived at Roma in November 1954 and completed acceptance test on June 1955.

\section{The 'make' Approach}

- The University of Pisa established its Centro Studi Calcolatrici Elettroniche (CSCE) with the aim of designing and building the Calcolatrice Elettronica Pisana (CEP) scientific computer. CSCE activities started at the end of 1954.

\footnotetext{
${ }^{1}$ Ref. [1], [2].
} 
- The internationally renowned firm Olivetti decided to enter the emerging computer industry. The Laboratorio Ricerche Elettroniche (LRE) was then established in order to design and prototype the Elea commercial mainframe. R\&D activities $^{2}$ begun at the middle of 1955 .

The already mentioned simultaneity of the four initiatives - a circumstance that did not imply any underlying overall strategy - clearly indicates that the urgency to enter the computer era was widely perceived throughout the country. As a very fruitful consequence, the efforts went through distinct approaches which complemented each other, avoiding competitive or conflicting situations: although resting on mutually independent scopes and resources, several kinds of collaboration had been set up since the beginnings. As a matter of fact, computing centers at Milano and Roma together with CSCE and Olivetti laboratories became the incubators for the first generation of Italian informaticians ${ }^{3}$.

The Polytechnic of Milano and INAC in Roma embraced the 'buy' approach in order to quickly have available an up-to-date powerful tool to afford computing applications that arose from the most varied needs of industry, engineering, physics, economics and mathematics itself; such was, after all, their institutional mission.

Worthy of mention that both acquisitions were almost entirely supported by ERP funds ${ }^{4}$. An even more important common trait of the two initiatives appears when appreciating what 'to buy a computer' really meant in 1954-55: far from being a ready-to-use product, the computer required in-house hardware maintenance and upgrades, often implying design and construction of original supplementary features.

Moreover, the machines were shipped 'nude', i.e. lacking of any software aid. Software development thus became the most impelling and demanding concern: service and utility programs (the forerunners of Operating Systems); algorithms for vectors and arrays handling; libraries of subroutines for frequently recurring problems like mathematical functions calculation. Until users themselves built up their loaders-interpreters and assembler-like symbolic languages, software had to be coded in machine language.

All these hardware and software tasks and duties concerned in a first moment the specifically owned machine but soon evolved into a generalized approach to every branch of computer science.

Final results of the 'make' approach, necessarily lasted several years even if the intermediate phases were full of scientific, technological and educational achievements.

${ }^{2}$ Centro di Calcoli Numerici: Numerical Computation Centre. / Consiglio Nazionale delle Ricerche: National Research Council. / Istituto Nazionale per le Applicazioni del Calcolo: National Institute for Applied Calculus. / Centro Studi Calcolatrici Elettroniche: Study Centre for Electronic Computers. / Laboratorio Ricerche Elettroniche: Electronic Research Laboratory.

${ }^{3}$ Let's at least mention other seminal initiatives. The Institute of Cybernetics at Napoli, founded by the theoretical physicist Eduardo Caianiello, mainly concerned with artificial and human neural networks from the Artificial Intelligence point of view [3]. DDA (Digital Differential Analyzer) installed at universities of Napoli, Bologna and Torino and the research that arose around them [4]. A small but effective enough electronic computer built at the University of Padova by Francesco Piva and others, expressly designed for teaching purposes [5].

${ }^{4}$ ERP: European Recovery Program, better known as 'Marshall Plan'. Apart from its political meaning within the cold war climate, ERP revealed highly effective in redeeming Western Europe from the disasters of the war. 
The CSCE project at Pisa originated from rather fortuitous (as well as fortunate!) circumstances and culminated with the construction of the CEP scientific computer. While completion of the CEP lasted until December 1960, a Reduced Machine (Macchina Ridotta) was ready as early as 1957.

Olivetti's LRE was able to complete in 1957 two prototypes based on vacuum tube technology. The final product was a fully transistorized mainframe: the Elea 9003. The first machine was delivered to a customer in 1959.

The time elapsed between start-up and successful outcome of the 'make' projects revealed of the same order of analogous projects carried on by most advanced Countries. A fact which deserve appreciation because - as far as technological and theoretical indigenous know-how were concerned - they started from almost tabula rasa.

To give but some examples, it is widely known that American and English computer projects massively recruited former military radar engineers, notably acquainted with non-linear (i.e. 'pulse' or 'digital') electronics, the basic technology of computer circuitry ${ }^{5}$. Italy instead almost completely lacked such already skilled personnel, due to the blindness of military staff who, during the war, denied resources to radar development: only a handful of single scholars were then familiar with digital electronics (some of them will be mentioned later on). For the same reason, domestic industries did not receive any stimulus to produce components needed by the 'new' electronics, namely special quality vacuum and cathode-ray tubes.

A further drawback could be found in the lack of knowledge about the relatively recent results in theory of computability and mathematical or symbolic logic: revolutionary findings by Gödel, Church, Turing, Post, Carnap and others began to affect Italian academy only in the post-war years and lasted even more to be appreciated as founding principles of theoretical computer science ${ }^{6}$. This was but a consequence of a long lasting supremacy of the idealistic culture that caused, among other, decline and fall of the Giuseppe Peano's school that flourished and gained international reputation at the outset of twentieth century ${ }^{7}$.

\footnotetext{
${ }^{5}$ To be reminded that 'linear electronics' originated from the invention of the triode vacuum tube (Lee DeForest, 1907). Its main concern was the undistorted (i.e. 'linear') amplification of continuous electric signals; it was then the core technology for radio communications.

${ }^{6}$ A single but outstanding exception was Corrado Böhm, whose brilliant career in the logic of computation began with his 1952 doctoral dissertation given at the Polytechnic of Zürich with E. Stiefel and P. Bernays as rapporteurs - concerning the first compiler ever written in its own language; the dissertation appeared in [6]. He emigrated to Switzerland to escape fascist racial laws against the Jewish and returned to Italy (1953) as an INAC researcher. During the formative years in Switzerland he became familiar with IBM and Bull punch-card equipment and, most of all, with Konrad Zuse's Z4 relay computer and its Plankalkül programming language. We shall meet Böhm on several passages of this narration, but here is the occasion to anticipate the celebrated 1966 Böhm-Jacpini theorem [7] that assured a theoretical groundwork for the 'Go To-less crusade' by Edsger Dijkstra and subsequent Structured Programming methodologies.

${ }^{7}$ During the first half of twentieth century, Benedetto Croce has been the undisputed champion of idealistic philosophy, according to which, roughly speaking, conceptual and hard sciences from mathematics to technology - were to be confined in the realm of instrumental activities, useful to mankind but deprived of cultural dignity; an approach that deeply biased public opinion and every degree of education. Croce particularly fought against the mathematisation of logic: logic, in his mind, had to be a hunting preserve for qualitative philosophical speculation [8].
} 


\section{Polytechnic of Milano}

The Polytechnic of Milano was - and still now-days remains - the most renowned engineering university throughout the Country. It was necessarily concerned with numerical calculations associated to the most varied engineering problems. From its long lasting tradition in this domain, let's select but a few examples ${ }^{8}$.

By 1928, Gino Cassinis - then at the beginning of his academic career - published a substantial seven hundred pages treatise on 'Numerical, Graphical and Mechanical Calculations'; Ercole Bottani, in 1935, issued an article titled 'Mathematics as seen by an Engineer', a sort of engineer's bible to approach mathematics; the same Bottani very likely unaware of Bush's Differential Analyzer - extensively experimented with physical systems which could be converted into analogic calculators, notably the 'Electrolytic Vessel': in 1945, under CNR's auspices, he established and directed a Centro Studi per i Modelli Elettrici.

Not surprisingly Gino Cassinis - elected in the meantime as the rector of the Polytechnic (and as the Mayor of Milano as well) - issued in 1951 a request to buy an electronic stored-program digital computer, to be supported with ERP funds. The request was accepted and, upon a screening of the not numerous machines made commercially available by the then emerging USA computer industry, a CRC 102-A model was chosen ${ }^{9}$. Not a huge machine, it was very cleverly engineered and equipped with a relatively cheap magnetic drum main memory; price/performance rate resulted highly competitive ${ }^{10}$.

Once the contract was signed, a young member of the Polytechnic was charged to carry-on the project: he was that Luigi Dadda who was to become one of the leading and driving personality for the development of informatics in Italy ${ }^{11}$. Dadda immediately left for Los Angeles, where he spent about four months at the CRC factory. He participated intensively in the making and testing of the machine, so gaining a full mastery of circuitry as well as of the new 'art' of programming. The computer arrived at Milano in October 1954; the installation resulted in a minor concern due to the compactness of the cleverly engineered machine that was shipped in fully finished units. The expressly constituted Numerical Computation Centre immediately started operations, while Dadda's first care was the training of colleagues (the first

\footnotetext{
${ }^{8}$ Ref. [9].

${ }^{9}$ The evaluation committee was composed by Cassinis, Bottani and Luigi Amerio, a mathematician formerly at Picone's INAC institute. Final screening benefited of knowledgeable suggestions by Samuel N. Alexander, the responsible of SEAC project at the National Bureau of Standards; he rendered himself friendly available while attending an international meeting at Milano.

${ }^{10}$ CRC (Computer Research Corporation) was born as a spinoff from Northrop Aircraft Corporation. Just in that period CRC was acquired by RCA (Radio Corporation of America) in order to establish its own entry into the computer industry.

${ }^{11}$ Dadda had worked with Bottani and, more important, was in the number of the few to have some previous experience with pulse electronics: the subject of his doctoral thesis (of 1945) concerned in fact a long-range pulsed radio link, a project he carried on under the supervision of Francesco Vecchiacchi, a distinguished professor of Electrical Communications. Among Vecchiacchi's achievements, the first statement (1939) of a formal theory for the bistable multivibrator (the popular 'flip-flop' electronic circuit) is perhaps the most commonly recognized [10].
} 
programmers) and hardware technicians. After being housed in better suited premises, the Centre was officially opened a year later ${ }^{12}$.

We have already considered the severe hardware and software tasks that were implied when buying a 'nude' machine in the years of infancy of electronic computing. All of them obviously occurred at the Polytechnic. Let's mention but the case of arithmetic capabilities of CRC 102-A: the machine was natively able to operate only on integer numbers while floating-point arithmetic was a mandatory need. Development of reusable software algorithms to perform 'floating-point by integer' arithmetic initially helped to overcome the problem, even at the cost of considerable overhead. An original hardware - activated by newly implemented commands - was then promptly designed and built to directly exploit floating-point arithmetic. The capacity of the drum memory was doubled by a new design of the read/write heads. Also the I/O performance of the machine - natively limited to a teletype - was enhanced by a hardware interface connecting a fast photoelectric punched-tape reader. CRC 102-A productive life lasted about eight years, until Olivetti gifted the Polytechnic with an Elea 6001 produced by the same firm.

Details of the manifold research activities carried on by the Centro di Calcoli Numerici as well as an enumeration of industries and scientific institutes who submitted problems can be found on several historical accounts and personal recollections by Dadda $^{13}$.

Anyway, there is no doubt that the most enduring contribution of the Centre has been to intensively lend its personnel to teaching duties: single courses on computerrelated disciplines started immediately and culminated into a formally stated specialization in Electronic Engineering (1960). Polytechnic of Milano fostered and licensed over the years a lot of highly skilled computer engineers; many of them undertook academic careers throughout the country, others went to industry and a considerable number worked lengthy abroad or migrated definitively.

\section{INAC, ICC, FINAC, CINAC}

The early story of INAC is intrinsically bound to the mathematician Mauro Picone, an outstanding character of this account.

Aged 29, he won a competition to fill a post of university full professor, but the outbreak of war (1914) caused enlistment as a second lieutenant and prevented him having a chair assigned. The ordnance staff became soon aware of the inadequacy of then available fire tables for heavy gunnery ${ }^{14}$. The urgent task of getting new tables ready was assigned to Picone. He worked intensively days and nights at a numerical solution of the quite intricate differential equations of exterior ballistic, only equipped with a small Brunsviga-like mechanical calculator. The new set of tables revealed timely and effective enough to get the author promoted at the rank of captain. Picone

${ }^{12}$ Later on (1958) the Centre was restructured on the base of two departments: Mathematical Section (Amerio) and Electronic Section (Dadda).

${ }^{13} \operatorname{Ref}[10],[11]$.

${ }^{14}$ Available tables were in fact prepared for lowland operations, while the Italian war front implied a need to shoot in the middle of Alpine mountains, often with a considerable difference of altitude between guns and targets. 
himself repeatedly quoted this war experience as the origin of his concern with numerical problem-solving and computing machinery.

By the end of the war, he taught analysis and calculus in several universities until arriving at Napoli, where, thanks to good offices of a colleague and a friend of him the economist Luigi Amoroso - the local bank in 1927 granted funds to establish an Istituto di Calcolo within the Faculty of mathematics; Picone's approach towards 'concrete' mathematics got to a visible institutional status. Upon moving in 1932 to the University of Roma - his definitive stay - he successfully fought to get the Laboratory moved with him and rose to the rank of CNR Institute: the already mentioned INAC $^{15}$.

The number of mathematical consultancies requested of and fulfilled by INAC is really impressive: we know from official records that they were 1,492 between 1937 and 1964, i.e. more or less 5 per month. It is to be noted that INAC permanent staff always remained very limited, but over the years it was complemented by a huge number of temporary collaborators and visiting members, often from abroad.

Activities at INAC were far from resting on mere computing tasks: it was instead common practice that problems submitted to the Institute implied refinement of already known mathematics and, often enough, development of brand-new theories and methods ${ }^{16}$. This explains the number and the quality of scientific papers and reports issued by the Institute, often appearing on international journals and proceedings too: starting from early years at Napoli, they were 163 in the 1927-36 period and 663 followed up to 1968. Picone authored or co-authored about 130 of them.

INAC was obviously equipped with standard mechanical calculators and other simple aids to computation but Picone willfully looked about for any kind of machinery useful to increase computing power and to speed up computation. We shall mention but a rough selection of his efforts that culminated in a sort of 'rush to the computer' ${ }^{17}$.

During the Thirties and early Forties, for instance, he was in touch with the already mentioned Bottani of Milano and came across equation solvers built - or merely devised - by Mallock in England, by Lorenzo Poggi and Lamberto Cesari at the University of Pisa and by Alessandro Boni, one of the INAC consultants ${ }^{18}$.

${ }^{15}$ Carrying on his initiative, Picone had to really fight against a long lasting tradition according to which academic research and teaching should be restricted to 'pure' mathematics. It is worthwhile mentioning that the authoritative mathematician Francesco Severi felt the need to establish in 1939 his own Institute of Higher Mathematics (Indam - Istituto Nazionale di Alta Matematica) ), in order to emphasize the distance between higher (i.e. pure) mathematics and the computing practices of applied mathematics as well as the implicit - but fallacious - superiority of the former.

${ }_{16}$ Moreover, it was mandatory for INAC to supplement numerical solutions with a careful evaluation of their reliability. Elaborate methods were then developed in order not only to reduce computing errors but also to certify an upper bound to the error that affected results.

${ }^{17}$ We owe to Angelo Guerraggio, Maurizio Mattaliano and Pietro Nastasi a quite extensive account of Picone's rush to computer. Their excellent writings [12] and [13] are based on the huge documentation that is available at the IAC Historical Archive, in Roma.

${ }^{18}$ The most recurring computing task at INAC was the solution of systems of linear algebraic equations, and the number of equations and variables was often so high to overwhelm capacity and accuracy of such otherwise ingenious contrivances. 
As soon as the first notices about automatic computers arrived in Italy, Picone was dazzled: the miracle he expected seemed at hand! ${ }^{19}$ He immediately realized that, lacking of such a new resource, INAC computing capabilities and its same internationally renowned prestige incurred the risk of obsolescence: computing centers abroad and institutes in which an electronic computer could be available were fated to supremacy. Picone soon activated two lines of attack:

- to send study missions to USA, England and wherever appropriate in order to gain first hand insight into the rapidly evolving state of the art;

- to raise funds and partnerships to build an Italian computer.

Bruno de Finetti - a distinguished mathematician then acting as a CNR consultant in 1950 visited coast-to-coast almost every significant US computer initiative and wrote an extensive account of the state of the art ${ }^{20}$. The same Picone together with his colleague Gaetano Fichera went to the United States for a quick survey. Other missions involved:

- Enzo Aparo and Dino Dainelli (they spent several weeks in Washington-DC at the Seac site, with the opportunity of coding and successfully running some mathematical program under the extremely kind supervision of Ida Rhodes);

- Michele Canepa (he was Olivetti engineer in charge of assisting Picone in view of a devised joint effort for an Italian computer; he was hosted for about eighteen month at Aiken's Harvard laboratory being there responsible for the design an set-up of a subsystem of the Mark IV computer);

- Giulio Rodinò and Mario Salvadori (who lengthily acted as Picone's watchers and 'ambassadors' across the States).

De Finetti, Kitz, and Rodinò went also to Teddington (London) where on March 1953 they attended an international symposium on automatic digital computing and wrote a careful report about it ${ }^{21}$.

Raising funds and/or partnerships for a domestic computer soon appeared a most difficult task. Preliminary talks with domestic industries - namely Olivetti and Microlambda - were soon abandoned ${ }^{22}$.

The proposal to make at INAC a clone of Harvard Mark IV - Picone suggested for it the name of Mark V - vanished as well, in spite of early friendly touches with Aiken, who also paid a visit to INAC.

For about six months INAC benefited of punch-card machines on free loan by IBM. The agreement was fostered by de Finetti, thanks to his long lasting familiarity with the managers of IBM's Italian branch. During those months de Finetti introduced

${ }^{19}$ Picone found an early account in a 1944 issue of Stars and Stripes, the popular magazine published by the U.S. occupation forces in Europe. Emphasis was on Howard Aiken's electromechanical Mark I, the IBM-Harvard University joint project. Later on, he became also aware of the ENIAC electronic computer. To be reminded that, although being technological prodigies, both machines were still not stored-program (à la von Neumann) computers.

${ }^{20}$ De Finetti's report [14] represented the early source of reliable and detailed information ever made available to the Italian scientific community.

${ }^{21}$ Ref. [15].

${ }^{22}$ We shall deal later on with Olivetti's ventures. Microlambda - established in 1951 near Napoli and leaded by Carlo Calosi - specialized in electronics and his flag product were radar systems produced under Raytheon licence. Microlambda later merged into Selenia, so becoming part of IRI (Istituto per la Ricostruzione Industriale: the huge and heterogeneous financial holding owned by the Government). 
Picone and his staff to the secrets of punch-card machinery, uncovering its unsuspected ability to deal with mathematical problems, far beyond customary business applications. According to the gentleman's agreement, free loan had to be followed by the rental of a more powerful IBM CPC (Card Programmed Calculator) but the fee exceeded INAC budget and the loan simply came to an end.

Meantime, an unexpected event occurred which captured Picone's energies: it happened that UNESCO - United Nations Educational Scientific and Cultural Organization - promoted a consortium of nations to establish an ICC - International Computation Centre - whose site was to be placed somewhere in Western Europe.

Several Countries issued their application to host ICC and the most convincing came from Switzerland, the Netherlands and Italy. All of them stressed the existence of institutes deeply concerned with computing: ETH at Zürich, Mathematisch Centrum at Amsterdam and INAC at Roma ${ }^{23}$.

Picone's will to win the competition became almost obsessive: he firmly thought that not only INAC's reputation but the national pride itself were implied. During 1950 and ' 51 , besides soliciting solidarity by the estimators of his Institute, he urged the Ministry of foreign affairs and the Italian representatives at UNECSO with a stream of memoranda ${ }^{24}$. The Swiss retreated, and UNECSO diplomacy had to choose between Amsterdam and Roma. In order to escape lengthy and delicate negotiations, they decided to seek the authoritative and super partes arbitration by Hermann $\mathrm{H}$. Goldstine, whose final advice (November 1951) privileged the Italian proposal ${ }^{25}$.

But it soon appeared that Picone had fought for failure. Considering the international importance of ICC, he had taken for granted that the Institute would be promptly equipped with the most updated computing machinery, easily accessible by INAC. Things went quite differently: big countries such as USA and U.K. did not subscribe to the Convention and ICC lived in a sort of interim limb until the statutory quorum of ten member nations was reached about ten years later ${ }^{26}$.

${ }^{23}$ ETH: Eidgenossiche Technische Hochschule (Federal Polytechnic).

${ }^{24}$ In a December 1950 memorandum that Picone addressed to the Minister, he emphasized the strategic value that ICC computing facilities could have in support of NATO (North Atlantic Treaty Organization) armed forces; in case of a sudden attack by Eastern enemy - he argued - Amsterdam was possibly fated to invasion while Roma remained strongly sheltered behind the front. In Picone's mind, such a really strange and ad hoc speculation risked gaining acceptance on the ground of notoriously massive use of computers by USA military staffs as well as of the fact that, just six month before, cold war degenerated into Korean 'hot' war.

${ }^{25}$ Herman Heine Goldstine - a mathematician of IAS (Institute for Advanced Study) at Princeton - was among the American computer pioneers: he participated to the ENIAC project and had been principal collaborator of John von Neumann for the IAS Machine project. Chapter 7 of his book [16] under the title 'The computer and UNESCO' contains details of the early story of ICC, up to its assignment to Roma. Goldstine was well aware that the Dutch Mathematisch Centrum was already familiar with computer theory and practice: as early as 1948-51 they built a relay machine called Arra and were currently working at a new version with vacuum tube and magnetic drum technology. (Incidentally, a similar situation existed at Eth, where Konrad Zuse's Z4 electromechanical machine was running since 1950 and the Hermet project - showing the influences both of Zuse's Z4 and Aiken's Mark IV - was under way). INAC lacked of similar activities but the undisputable superiority of the Institute prevailed in Goldstine's mind as far as mathematical research and expertise in numerical methods were concerned.

${ }^{26}$ On the occasion, the firm Olivetti gifted ICC with one of the first shipped Elea 6001 scientific computer. Later on ICC became IBI (Intergovernmental Bureau for Informatics), but its aim and scope progressively failed to fit the state of art and UNESCO, in 1988, deliberated its dismissal. 
The lengthy struggle came to an end when INAC got the opportunity to buy with ERP funds a commercially available computer and Picone, pressed by urgency, unwillingly abandoned the idea of an Italian machine ${ }^{27}$. A powerful Ferranti Mark I* was selected and the contract readily signed ${ }^{28}$. Two INAC mathematicians - Corrado Böhm and Enzo Aparo - went to Ferranti works at Moston (Manchester) in order to learn programming. They also ascertained the machine's capabilities by coding and running a program for the resolution of a system of 62 linear algebraic equations with as many variables.

The Ferranti-INAC computer, soon christened FINAC, arrived at Roma in January 1955 and became ready for acceptance test in June 1955. In contrast with the CRC machine at Milano, Mark I* was a huge one, shipped piece by piece - small subassemblies or even single components - so that its overall assembly resulted a not at all trivial concern and required several months. Another difference with the experience of the Polytechnic was that INAC personnel currently included only mathematicians, peoples not acquainted with oscilloscopes, vacuum tubes and electric welders; the Institute hired then in a hurry some young engineers to be trained by Ferranti technicians in the course of assembly ${ }^{29}$. The opening ceremony (December 1955) was a memorable event, held before the President of the Republic; Sir Vincent de Ferranti attended too and didn't omit to emphasize the Italian origin of his ancestors.

As expected, activities at INAC - as well as at the closely linked Faculty of mathematics - were deeply affected by the availability of a powerful computer. Things went about the same as happened at the Polytechnic of Milano and we will not to return either to the already discussed tasks and duties that occurred when buying a 'nude' machine nor on the steps that marked the rise of a prolific school for computer scientists, researchers and educators.

${ }^{27}$ The extreme effort had been the proposal to hire Samuel Alexander as project leader for a 'made in Italy' computer - obviously a SEAC-like machine - to be built with still granted ERP funds.

${ }^{28}$ At an early stage of negotiation, Ferranti Ltd. was extremely doubtful - not to say worst about the reliability of Italian counterpart. Let's quote from a letter by B.V. Bowden (Ferranti marketing manager) to Lord Halsbury (the chief of NRDC: National Research Development Corporation). The letter is dated $21^{\text {st }}$ April, 1953.

"I am not at all sure in my own mind if their ideas as to how it [a computer] is to be used are any clearer than were those of that lamentable Committee ..."

"A friend of us ..., who spent some time in Rome, gave me to understand that negotiations of this kind are conducted in Italy on a rather unusual way which involves a fair amount of what one had perhaps best describe as 'rather delicate personal negotiations'."

"... we are beginning to wander whether they are merely collecting a few quotations in order the better to give the final contract to a firm owned by some relation of one of the Ministers who is more interested in keeping the 1/2million pounds in Italy than in producing a computing machine."

In 1990, Jeoffry Tweedale - who was then the curator of the National Archive for the History of Computing at the University of Manchester - came across this letter among the NRDC papers and kindly passed to the author together with other documents of same concern. The letter has been entirely reproduced in [17].

${ }^{29}$ The first engineers hired by INAC were Giorgio Sacerdoti - who had just completed a doctoral thesis on computer electronics, perhaps the earliest in Italy - Paolo Ercoli and Roberto Vacca. Ercoli became the most active mover of INAC engineering activities while Sacerdoti soon joined Olivetti's Elea project. 
According to Paolo Ercoli, "Maintenance and modifications of the FINAC were carried on by the Institute, as was customary in those years, so that machines that were identical when bought could be changed progressively and have, after a few years, rather different capabilities." 30 Among several hardware improvements, the most effective had been new circuitry for overflow automatic detection in arithmetic operations and a feature to handle double precision arithmetic ${ }^{31}$.

On the side of software, Corrado Böhm, Dietrich Prinz and others developed the Intint symbolic language - together with its own interpreter - which almost eliminated the need of machine-language programming.

During the second half of the fifties several members of INAC taught the first courses on computer programming and computer science at the Faculties of mathematics, physics and engineering of the University of Roma.

In 1960 Picone retired and Aldo Ghizzetti succeeded as INAC director; in May 1975 , on the occasion of his $90^{\text {th }}$ birthday, the Institute was dedicated to its founder with the new - and nowadays persisting - denomination IAC 'Mauro Picone' ${ }^{32}$.

FINAC revealed an exceptionally long-lived machine: switch off occurred on June 1967. However, its unavoidable obsolescence became clear much earlier. When the University of Roma bought a general purpose Univac 1108 machine, powerful enough to fulfill administrative and scientific needs of all faculties and institutes, it seemed that FINAC would be superfluous.

INAC disagreed and resumed the idea of setting up an original computer; its director Aldo Ghizzetti, in 1961, addressed then a proposal to Olivetti, which promptly assured a quite robust collaboration.

A joint project was then agreed, according to which hardware implementation and set up was Olivetti's concern: the outcome of the project had to be a full working prototype owned by INAC - the CINAC (Computer INAC) - while Olivetti had to assume the prototype as the ground for an innovative industrial product - the devised Elea 9004 series. The outstanding feature of CINAC / Elea 9004 consisted in its being a 'stack' machine with zero-address instructions, the same architecture that inspired the almost contemporary Burroughs B5500 computer. The joint initiative was an unusually 'software driven' project, meaning that it arose from the convergence of Olivetti and INAC ideas about a machine particularly suited for efficient compilation of programs written in some Algol-like language ${ }^{33}$.

Construction of the machine started at Olivetti works in early 1963 and culminated in February 1966 with CINAC delivery, but the seemingly successful outcome of the project is misleading. On Olivetti's side of the story - on which we shall return hereafter - the DEO (Divisione Elettronica Olivetti) was sold to General Electric and the

\footnotetext{
${ }^{30}$ Ref. [18].

${ }^{31}$ FINAC's native capacity to operate with 40 bit binary numbers increased to 80 . This was in accordance with the quite peculiar nature of INAC's computations that privileged precise (i.e. with as many as possible digits) rather than floating-point arithmetic.

${ }^{32}$ The ' $\mathrm{N}$ ' (for Nazionale) seemed no longer appropriate due to the spread of scientific computation centers that occurred in the meantime.

${ }^{33}$ Inside Olivetti, it was Mauro Pacelli - the responsible of LRE software department - to issue an early proposal. At the same time, the INAC logicians - among them Giuseppe Jacopini and very likely the same Corrado Böhm - cultivated similar ideas. Paolo Ercoli, on the side of INAC, became the most concerned with the development of the project.
} 
devised Elea 9004 series was abandoned because it didn't match the product policy of the Americans; GE did not discontinue collaboration on CINAC but reduced resources to the minimum, whence a notable delay in hardware shipment. INAC, on its own, faced the problem of transferring to the new machine the huge wealth of FINAC software accumulated over the years. The hypothesis of coding it anew was unfeasible, so that they went to a tradeoff: a sort of hardware emulator of FINAC on the CINAC was set up in a hurry. At the same time, due to the lack of resources, the development of interpreters or compilers specifically designed for CINAC never went to satisfactory results. As a result, the innovative and powerful capabilities of CINAC were left hidden and almost unused. Soon after (1969) the final act occurred: the mathematician Guido Stampacchia succeeded Ghizzetti as INAC director and decreed the end of its hardware and software activities ${ }^{34}$.

\section{CSCE, CEP and the Pisa District}

During the Forties of last century, elementary particle accelerators - huge and costly machines of ever growing dimensions that inaugurated in USA the age of 'Big Science' - became the most powerful tool for the advancement of experimental particle physics and outdated the cosmic rays approach that was still alive at Pisa ${ }^{35}$. The construction of a quite advanced accelerator thus became a major concern of the Istituto Nazionale per la Fisica Nucleare (INFN), which issued a call for tenders ${ }^{36}$.

Several local governments for whose territories Pisa was the cultural centre of attraction, had created a consortium in order to give financial support to the University for some prestigious scientific undertaking: the particle accelerator seemed an extremely propitious occasion. Unfortunately for Pisa, the University of Roma was able to reinforce its own application with more than twice the financial support; the accelerator thus became the $1 \mathrm{GeV}$ elecrtrosynchrotron at the INFN laboratories of Frascati, in the surroundings of the capital city ${ }^{37}$.

At Pisa they worked to guess a new destination for already gathered funds and the answer - that had nothing to do with the University's scientific tradition - arose as a fortuitous consequence of the accelerator affair: during August 1954 Marcello Conversi, Giorgio Salvini and Gilberto Bernardini - all of them concerned with the project of the particle accelerator - met the Nobel laureate Enrico Fermi at a Summer School in Physics and, while relaxing in conversation, asked for his advice. He

${ }^{34}$ An account of what happened appears in chapter 7 (pp. 417-420) of [22].

${ }^{35}$ The University of Pisa had a strong tradition in the domain of elementary particle physics; it dated back to the 'school' of Bruno Rossi, who, during the Thirties, pioneered the use of cosmic rays as an inexpensive - but rather erratic - source of particles to be submitted to experiment. Worthwhile mentioning that his experimental apparatus included innovative 'coincidence' and 'anticoincidence' electronic circuits that, in forthcoming computer jargon, became popular as AND and XOR logic gates. [23] The young physicist Marcello Conversi we shall meet him hereafter - was a great expert of such techniques that belong to non-linear electronics.

${ }^{36}$ Istituto Nazionale di Fisica Nucleare: National Institute of Nuclear Physics. INFN was founded in 1951 and the physicist Gilberto Bernardini became its president.

${ }^{37}$ Funds granted by Pisa and Roma amounted to 150 and 400 million Lira respectively, roughly equivalent to 2.2 and 5.8 million Euro. 
promptly replied "build an electronic computer!" 38 It was not at all a boutade and Fermi agreed to express his mind in a letter to Enrico Avanzi, the rector of the University of Pisa. A suggestion issued by Fermi was immensely authoritative so that Avanzi did not hesitate: the university nominated a three member steering committee - Marcello Conversi (Chair), Alessandro Faedo and Ugo Tiberio ${ }^{39}$ - and the CSCE was established as soon as March 1955 on the ground of two preliminary reports that Conversi asked for to Alfonso Caracciolo (a detailed survey of the international state of the art $)^{40}$ and Mario Tchou (an overall project plan with the estimate of duration and human and financial resources $)^{41}$.

Tchou had been just hired by the Olivetti firm and his welcomed participation to the preliminaries of the CEP project was but a sign of Olivetti's intention to become a partner. After a period of friendly collaboration, in May 1956, the University and Olivetti signed a formal agreement: CSCE offered almost free access to inventions and patents that could arise in the course of the project, while the Olivetti counterpart assured a yearly financial contribution of 10 million Lira, free loan of skilled engineers from its own staff and, whenever appropriate, special discounts on auxiliary equipment. It was not an operation of authentic technological transfer - in the style of the close link between the University of Manchester and Ferranti Industries - but represented in Italy a notable and early case of joint effort between academic research and private industry.

Under the supervision of Conversi's steering committee, CSCE, as customary, was structured into a Logic-Mathematical and an Engineering-Electronic section whose leading personalities formed the Acting Group for the technical management of the project ${ }^{42}$.

${ }^{38}$ Upon receiving the 1939 Nobel Prize for physics, Fermi emigrated to USA to escape the fascist racial laws (his wife came from a Jewish family). After the war he had occasion to make intensive use of electronic computers, especially of the Los Alamos MANIAC machine. That of 1954 had to be his last trip to Italy: a year later he died in Chicago, aged fifty four.

${ }^{39}$ They represented the most concerned Faculties: Physics (Conversi), Mathematics (Faedo) and Engineering (Tiberio). We already mentioned Conversi's previous experiences with electronics. Faedo undertook a brilliant academic and political career (Rector at Pisa, President of CNR, Senator of the Republic) along which - much like Luigi Dadda - he never ceased to authoritatively promote and support the development of informatics in Italy. Tiberio, during the war, had led an electronic laboratory aimed to set up Radar systems for the Italian Navy: a research effort that aborted due to the blindness of higher military authorities.

${ }^{40}$ The 'Caracciolo report' largely drew (and fairly quoted in bibliography) the already mentioned articles [14] and [15] by de Finetti and others.

${ }^{41}$ Conversi circulated the envisaged initiative among the scientific community. Answers and comments were positive and encouraging enough, with a notable exception: Picone vividly objected against wasting precious financial resources in an initiative that appeared superfluous because Italy already had the FINAC computer. He minded that a single powerful machine would suffice for the entire Country. It was of course a short-sighted - and possibly 'egoistic' - opinion; moreover, Picone was still unaware of what already happened at Milano.

${ }^{42}$ Acting Group members: the director of L-M (Caracciolo) and E-E section (part-time, until April 1956; Giuseppe Cecchini until February 1961, when Giovanni B. Gerace succeeded), Elio Fabri (L-M section) and Sergio Sibani (E-E section). Tchou, Cecchini and Sibani, together with Vladimiro Sabbadini, were the four engineers that Olivetti assigned to the CEP project. Worthwhile mentioning that Corrado Böhm, on leave from INAC, joined the L-M section for one year (October 1958 - October 1959). When the CEP computer entered regular service (1960) a third section - Gruppo Servizio Calcoli: Computer Service Group - was formed in order to manage the machine, define work schedule and assist users. 
In accordance with 1955 original schedule, the Reduced Machine (MR: Macchina Ridotta) was completed in December 1957 and became the first computer entirely designed and built by an Italian team.

Despite its limited capacity, MR was powerful enough to serve as an effective computing tool: several anything but trivial computations were performed in the matter of number theory, Monte Carlo methods, atomic and particle physics, crystal structure and other. Setting up of MR mainly functioned as a training laboratory where CSCE personnel acquired mastery on every facet of a computer project.

The large CEP computer had been initially conceived as a mere enlargement of the $\mathrm{MR}$, to be accomplished with the addition of a magnetic drum and a line printer as well as by extending word length from 18 to 36 bit. The rapidly evolving state of the art and the will of an advanced and much more powerful scientific computer lead to a new and completely different design: as a matter of fact, the almost unique tangible heritage of MR experience was the technology of magnetic core high-speed memory. The radical change of the project benefited of further financial support by INFN and CNR but implied a one year delay over the original schedule.

On the ground of the new design ${ }^{43}$, setting up of the CEP computer started on March 1959 and was completed on December 1960. MR was completely disassembled in order to reuse its costly components, vacuum tubes above all.

As far as hardware is concerned, CEP appeared as an hybrid computer: traditional vacuum tubes combined in fact with the emerging transistor technology, that firstly concerned the project in 1956 by means of the doctoral dissertation by Franco Denoth under Gerace's supervision - about 'Transistor arithmetic unit for an electronic digital computer'. The use of transistors in some units of the machine was carefully evaluated in view of their not yet ascertained reliability: the hybrid trade-off was finally agreed due to the ever better performances of transistors and, most of all, in order to reduce space occupancy and power consumption, even at the cost of a double feeding system to fit the quite different voltage and current working-levels of tubes and transistors.

CEP was a microprogrammed computer and the microprogram was registered on a high-speed eprom ( $0.1 \mu$ s access time) based on the original design introduced by Tom Kilburn for the Manchester MUSE-ATLAS machine ${ }^{44}$. The two magnetic drums - one on-line and one spare - were manufactured at the New Canaan laboratories of Olivetti Corporation of America (see next paragraph), but drum control and I/O interface circuitry remained a CSCE concern. A tape control unit connecting six tape drives was added after completion of the project.

Caracciolo's L-M section carried on intensive research on abstract computer science but its most effective contribution to the project was the development of system and support software that decisively enhanced and made easy an effective use of the machine: let's mention at least a linker-loader - aimed to automatically extract from a library and link to the main program the subroutines called for by the

\footnotetext{
${ }^{43}$ In order to check in advance the soundness of the new logical design, a software simulator of the CEP was developed at FINAC.

44 The eprom was constructed from a 256x256 mesh of conducting wires mounted over a soft plastic. Contrasting with the usual technique of fixed cores, ferrite rods of $1 \times 10 \mathrm{~mm}$ were inserted in (and removable from) the interstices of the mesh wherever a 'ONE' bit were to be stored [24][29].
} 
latter - as well as a Fortran II compiler, augmented with a series of instructions intended to take advantage of peculiar hardware features of the $\mathrm{CEP}^{45}$.

CEP official inauguration was held on November 1961and Faedo - University's Rector since November 1959 - had the privilege to welcome the President of the Republic Giovanni Gronchi, who was not new to such happenings. More meaningful than that mundane ceremony was the attention that authoritative analysts dedicated to the completion of the project (see Box 1). CEP productive life lasted eight years, with about 3,000 hours per year of working time.

\section{BOX \# 1: Some comments in praise of CEP}

The University of Pisa's Computer Centre is engaged in logical design, computer programming, numerical analysis, and electronic design and construction. The Computer development work is among the most advanced observed in Europe.

I.L. Auerbach [24]

... it is unfortunate that the CEP was not completed earlier than 1960, before the large-scale importation of foreign computers, when it might have had a wider influence on computers and computer application in Italy ...

N.M. Blackman [30]

... though only transistorized in part, CEP is the most advanced and the most powerful university made computer of the West-European Continent.

J.L.F. Kerf [31]

Needless to say the CSCE members tightly collaborated with the University to give regular courses concerning almost every branch of computer science. Educational concern of the University of Pisa culminated in 1969, when a specialization degree in Scienza dell'Informazione (Information Science) was formally instituted. According to Italian regulations, such a decision had to be decreed by the Ministry of Education. Faedo submitted then a proposal as early as July 1967, supported by an intended curriculum that resulted from an inspection of analogous courses already experienced abroad as well as from discussions with Luigi Dadda, of the Polytechnic of Milano, in order to avoid superposition with the specialization in Electronic Engineering. The decree lasted until March 1969 and Faedo later discovered that the lengthy hesitation of the minister had to be ascribed to quite surprising negative advice by the CNR committee for Mathematics ${ }^{46}$. Faedo was obviously right: about five hundred students promptly optioned the new specialization and, over the years, many other universities followed the example ${ }^{47}$.

Upon completion of the project, CSCE incurred an identity crisis: funds that were specifically granted for setting up the CEP computer were exhausted and the same support by Olivetti necessarily came to an end. Fortunately enough - after a quite dramatic period during which short-term survival was allowed by a research project

\footnotetext{
${ }^{45}$ About the Fortran-CEP, Nelson M. Blackman commented: "Eight people have been developing a FORTRAN Compiler for the CEP; this is an unusually large effort for Europe." [30], p. 264. The team was led by Otello G. Mancino [32].

${ }^{46}$ On 1972 Faedo himself became the president of CNR.

${ }^{47}$ Ref. [28].
} 
on digital solid-state technologies committed by Euratom - CSCE, in 1962, was elected as an Institute of CNR, not exclusively bounded to the CEP mission.

Anyway, CSCE activities had to be redirected: when the same glorious CEP was switched off, it was radically restructured into the IEI Institute (Istituto di Elaborazione dell'Informazione) aimed to a broad spectrum of research in - and applications of - information technology 48 .

It was not enough and the Pisans looked around for further opportunities. Faedo was particularly concerned: among others, in 1963 he was able to catch for Pisa the donation by IBM of a 7090 powerful computer ${ }^{49}$. An agreement between the University and IBM-Italy led to the establishment of a new scientific centre named CNUCE (Centro Nazionale Universitario di Calcolo Elettronico $)^{50}$.

Thanks to the presence of prestigious scientific institutions and the on-site availability of skilled manpower fostered by the University, Pisa became a quite attractive location for an ever growing number of undertakings concerned with Information Technology, ranging from research centers of very large industries to small ventures by groups of entrepreneur-scientists: a creative mix of science and business in the perfect style of an high-tech district. It was but the ultimate fall-out of Fermi's early intuition and of the formative years of the CEP project.

\section{$5 \quad$ Olivetti}

The firm Olivetti was established in 1908 by Camillo Olivetti with a small typewriter factory at Ivrea, a town near Torino. Along three decades the business grew at a steady rate on the domestic and foreign market until Adriano, the eldest son of the founder, succeeded in 1938 when he was thirty seven. Under his clever and resolute leadership $^{51}$, Ivrea's enterprise undertook a substantial upwards jump that became

${ }^{48}$ IEI was headed by the mathematician Gianfranco Capriz until 1979, when Franco Denoth succeeded. Building up of entire hardware systems obviously reduced to a minimum; a notable exception was the Tau2-Taumus, an early sound synthesizer that enabled real-time recording, composition, manipulation and reproduction of music. It was an IEI-CNUCE joint project (1973-75); the composer Pietro Grossi acted as music advisor and the system functioned until 1987 at the Conservatory 'L. Tartini' in Firenze.

${ }^{49}$ IBM donated three 7090 to European prestigious universities; the other two went to London and Copenhagen. The choice of Pisa as the third recipient was influenced by the warm familiarity between Faedo and Eugenio Fubini, who was then the IBM vice-president responsible for that business. A familiarity that dated back to the late Thirties, when they were both young assistants at the University of Roma; Fubini left Italy in order to escape the fascist racial laws against the Jewish.

${ }^{50}$ CNUCE as well, in 1974, was elected to the rank of CNR Institute. Among its manifold activities, let's mention the Laboratory of Computational Linguistic, where Antonio Zampolli and his assistants resumed, refined and broadened the domain of the pioneering work of the Jesuit father Roberto Busa.

${ }^{51}$ His unparalleled style of management combined the restless care for business with the strong believe in the social responsibility of an industry; an attitude that materialized into manysided benefits towards workers, their families and the surrounding human community. Tradeunions often accused Adriano of subtly hidden paternalism aimed to better submit the workers; on the opposite side, the quite conservative Manufacturers' Association (Confindustria) treated him as a dangerous revolutionary utopist and someone arrived to boycott Olivetti's products. Being an exquisitely learned personality, he fostered over the years a sort of cultural circle - comprising architects, sociologists, psychologists and artists - strictly tied to various practical activities of the firm [33][34][35]. 
particularly intensive during the post-war years, making Olivetti a multinational industrial holding and a leader in the worldwide market of office equipment ${ }^{52}$.

Letting aside the already mentioned negotiations with INAC, Olivetti became directly concerned with electronic computing by means of two separate initiatives.

The first one was Olivetti-Bull, a fifty-fifty company established in 1949 in order to market in Italy the punch-card equipment produced by the French Compagnie des Machines Bull, the principal opponent of IBM in Europe. Later on, Bull products evolved into early small sized electronic computers: the Gamma3 and the Gamma3ET (Extension Tambour, i.e. with a magnetic drum memory). Olivetti-Bull did not contribute to Olivetti's technological know-how but allowed its personnel to become acquainted with computer programming and, most of all, to fight against the commercial aggressive policy of IBM $^{53}$.

The second one was the establishment in 1952 of an Electronic Laboratory at New Canaan (Connecticut). The laboratory acted in practice as a private territory of Dino Olivetti - Adriano's youngest brother - and Ivrea's headquarter ever considered it as as a mere observatory over the USA state-of-the-art. Things went partially differently, mainly due to the skilled technical directorship by Michele (later changed into Mike) Cànepa $^{54}$. The laboratory, worked in fact on several electronic products and an OlivettiGBM (General Bookkeeping Machine) was mentioned in a 1955 survey of computers available in $\mathrm{USA}^{55}$; it was a small machine with 112 vacuum tubes, 450 crystal diodes and a magnetic drum storage. The laboratory specialized on magnetic drums, that apparently became the sole marketable product but with almost negligible result, even if two drums arrived to fit out the CEP computer. As sought from the Italian motherhouse, New Canaan laboratory appeared only a source of expenditure and it was then shut in 1961. Dino Olivetti went back to Italy while Cànepa, after a brief and rather disappointing stay at the Olivetti LRE, definitely migrated to the United States ${ }^{56}$.

In Adriano's mind, electronics never represented a departure from the traditional and successful business of office equipment: his long-sighting instinct conceived instead the electronic computer - better to say, the electronic data-processor - as the core of the 'office of the future' ${ }^{57}$. In other words, he clearly felt that the 'computer by

${ }^{52}$ New plants were built in Italy and in abroad strategic locations; an efficient worldwide commercial network was established; mechanical calculators and accounting machines flanked traditional typewriters as flag-product but other products arose like teletypes, office steel furniture, numeric-control machine tools.

${ }^{53}$ The first Gamma3 Italian installation occurred in 1953. The engineer and former commander of the Navy Ottorino Beltrami was the director of Olivetti-Bull, while the very young Elserino Piol emerged as the technical and sales-supporting driving person, thus beginning a brilliant career as a high level manager. The essay [38] contains a detailed history of Olivetti-Bull.

${ }^{54} \mathrm{We}$ already met him as an Olivetti advisor to Picone and a temporary member of Aiken's crew for the Mark IV project.

${ }_{55}^{55}$ Ref. [37].

${ }^{56}$ A further witness of such unfriendly relationship can be found in the fact that, according to a 1959 announcement of the Elea 9003 [39] the machine had to be equipped with an auxiliary mass storage of up to three magnetic drums - very likely supplied by New Canaan - but this feature was in fact never implemented.

57 It seems likely that Adriano's vision could be influenced and comforted by the early (about 1950) commercially available and business-oriented computers built by Eckert and Mauchly in the USA (the Univac, soon acquired by Remington Rand) and by Lyons Industries in England (the LEO, meaningfully christened Lyons Electronic Office). No doubt that Adriano Olivetti was well aware of both initiatives. 
the scientists for the scientists' was to be superseded by the 'data-processor by the industry for the market ${ }^{, 58}$.

He was nevertheless perfectly conscious that a strong scientific and technological groundwork was the prerequisite to afford the computer market with an original and competitive product. The first move was to find out a skilled and reliable person to lead the R\&D activities of the firm in the domain of electronic computers. Adriano ever had the ability to immediately perceive people's personality; during a trip to the United States, he met Mario Tchou, a thirty years old professor at Columbia University, and was touched by his human and professional traits ${ }^{59}$. Within a few months, in 1954, Tchou was hired with the twofold heavy responsibility to contribute at CSCE's early activities (see latter paragraph) and to set up the already mentioned Olivetti LRE research laboratory. According to Adriano's intuition, Tchou emerged as an excellent manager as well as a resolute but friendly leader of the LRE team, a small group of engineers and physicists - all of them in their twenties - carefully selected by himself.

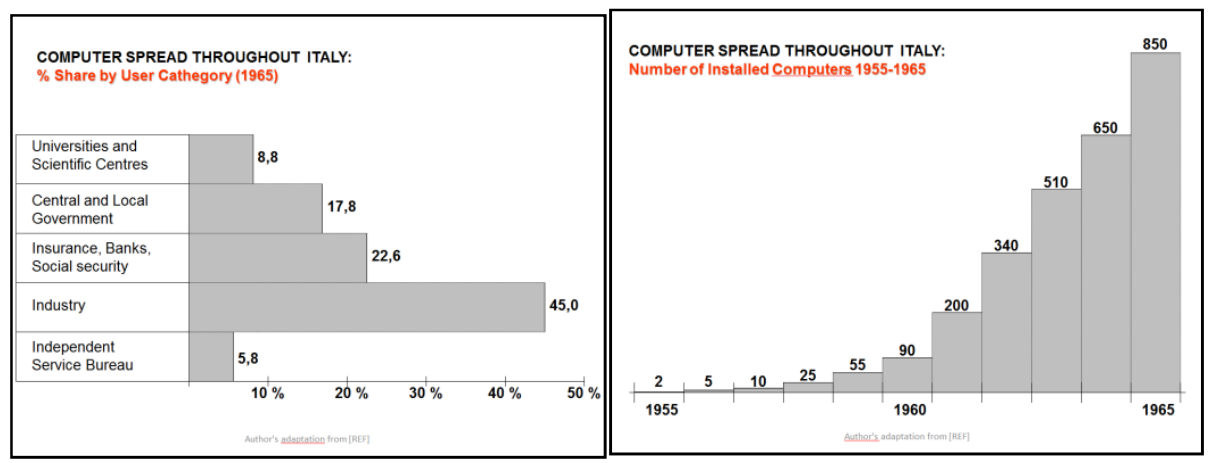

Fig. 1. and 2. Computer spread throughout Italy

Even if CSCE's and Olivetti's initiatives shared the courageous 'make' approach, we owe it to point out some intrinsic difference between them. First of all, before the advent of the general purpose computers, the architecture of a scientific machine markedly departed from that of a business-oriented one. As a further difference, whilst the CEP was intended as a one-of-a-kind machine to be used in a self-contained laboratory-like environment, the Olivetti computer was conceived as an industrial product; it had therefore to fulfill specific needs of mass production as well as easy of maintenance, ergonomics and aesthetic appeal. Last but not least, CEP project was carried on in the style of an 'open' contribution to the advancement of science, thus originating a

58 Adriano's vision anticipated in fact the observed trend. As far as Italy is concerned, the histograms in figures 1 and 2 witness both the rapidly spread of computers - all of them but the single CEP were manufactured by industry - and the rapidly \% decrease of scientific users. Both histograms are the author's elaboration from the Dadda's 1967 report [36].

59 Mario Tchou was born in Roma on 1924 and ever lived there; his father was in fact a diplomatic officer at the Chinese embassy. When the war ceased he went to the USA, becoming bachelor in electrical engineering (1947), Master of Science in physics (1949) and associate professor of electrical engineering at Columbia University (1952). 
flush of papers detailing scientific and technical achievements; Olivetti's policy according to common practice in industrial research - privileged instead confidentiality so that articles and reports - anyway of more or less promotional scope - appeared only in the latest phase of the project.

In early 1956, after a period of hospitality at the University of Pisa, LRE started operations. It was housed in a pleasant ancient villa at Barbaricìna, a suburb of Pisa, and the LRE crew became currently known as the 'Barbaricina guys'. With the exception of Giorgio Sacerdoti and Martin Friedman, LRE members almost lacked of previous specific knowledge ${ }^{60}$. When Tchou selected them, he mostly appreciated in fact their intellectual potentialities, so that they only needed brief and intense training to plenty master the fundamentals of the new science. While Sacerdoti knowledgeably assisted him in defining the overall design of the machine, Tchou committed to each member of the staff the care of a specific functional subsystem and regular meetings were held to check the interfaces.

It seemed almost incredible that at the end of 1957, well in advance over the initial schedule, Tchou and his guys - whose number grew up to thirty - completed the Zero Machine (Macchina Zero), the vacuum tube prototype of Elea computers, with a transistorized tape control unit designed by Lucio Borriello ${ }^{61}$. A second prototype immediately followed and it was only at this point that Adriano officially confirmed electronics as a new concern of his industry and allowed further investments.

It was not enough because Tchou insisted that Olivetti had to afford the market with a first class product and full transistorization was absolutely needed. Saving the logical and functional design, circuitry had to be completely redefined; a quite demanding task that LRE quickly accomplished so that, in autumn 1959, the production plant was able to deliver the Elea 9003, one of the worldwide earliest - possibly the first - solid-state commercially available computers.

Other notable features were: magnetic core memory expansible from 20,000 up to 160,000 characters in modules of 20,$000 ;{ }^{62}$ variable length memory fields; interrupt signals that allowed the simultaneous execution of three programs; up to twenty magnetic tape units; last but not least, an ergonomic and pleasant appearance invented by the architect Ettore Sottsass.

${ }^{60}$ Sacerdoti came from the engineering group of FINAC. Friedman, a Canadian engineer, previously worked with Ferranti Industries at Manchester.

${ }^{61}$ An assessment of synonymous names that often appear in literature:

- Macchina Zero: the vacuum tube prototype (tape control unit made with germanium transistors) built up at Barbaricina on rough laboratory racks.

- $\quad 1 \mathrm{~V} /$ Elea 9001: the same Macchina Zero (\#1 Vacuum tube prototype) moved to Ivrea, dressed in a suitable office style and used as a complement to the punch-card data processing centre.

- $\quad 2$ V / Elea 9002: \#2 Vacuum tube prototype; tape control unit made with silicon transistors; installed at Milano as a demo-centre and software laboratory.

- $\quad$ 1T / Elea 9003: \#1 wholly Transistorized prototype and production model at the Borgolombardo factory.

Elea is a contraction of Elaboratore Elettronico Automatico.

${ }^{62}$ A character was coded into a 'Byte' of six bit plus one for parity check. Filippazzi invented a method that halved the bit-selection circuitry; the invention was patented by Olivetti and licensed to Plessey in England. 
The computer factory was established at Borgolombardo, near Milano, where the research group of LRE also moved. Production activities together with the setting up of a commercial organization - including hardware and software customer assistance - became the most demanding and financially-draining concern of Olivetti. It soon appeared that the computer business could benefit from the commercial experience already matured by Olivetti-Bull, also because punch-card and electronic data processing shared the same category of customers. Olivetti then acquired $99 \%$ of Olivetti-Bull and merged it into the DEO (Divisione Elettronica Olivetti), headed by Ottorino Beltrami and with Elserino Piol as marketing manager.

The exciting times of Barbaricina were over, but intensive research on new products continued under Tchou's directorship, willingly flanked by Roberto Olivetti to which his father Adriano, since the beginning, committed special care to the electronic branch. The most valuable achievement was the mid-range Elea 6001 computer that had a micro-programmed architecture: it was delivered in 1961 and became nearly standard equipment for university computing centers. To improve sales of this successful product, Piol insisted to slightly modify the machine into the Elea 6001-C model ('C' for Commerciale), better suited for business applications.

When considering the activities that LRE carried on in the domain of software, some weaknesses appear in retrospect, especially in comparison with the experiences we have discussed in former paragraphs.

During the early phases of the Elea project, attention was almost exclusively focused on hardware while the critical role of software begun to be appreciated only upon completion of the Zero Machine. The care of software was committed to a small - and perhaps under-sized - group led by the mathematician Mauro Pacelli, who privileged the theoretical study of high-level programming languages - the so-called 'logic programming' - leaving almost unattended the domain of application software; an approach that compelled the commercial division to pursue almost at random the software requirements issued by customers.

To give but an example, the lack of a software supervisor left to the application programmer the exceedingly delicate handling of concurrent programs, so that multiprogramming - a distinguished feature of Elea 9003 - rested almost unused.

Later on, the LRE logic programming team defined an original Algol-like language, named Palgo, and built a compiler for the Elea 6001. But it happened that the 6001 users - almost all of them were scientific centres - urgently asked for a Fortran compiler and it was the commercial division, not the LRE, to fulfill in a hurry such a request ${ }^{63}$.

The massive import of solid-state components concerned not only Olivetti but also other industries, namely for consumer electronics, giving the opportunity to set up an autonomous production in Italy. Tchou and Roberto convinced Olivetti to catch the opportunity: the SGS company (Società Generale Semiconduttori) was then established in association with Telettra and started production under Fairchild

${ }^{63}$ It should be remembered that high-level computer languages were then in their magmatic infancy, far from benefiting of much later standard definition by super partes authorities. It seems likely that Pacelli refused Fortran in order not to appear as an IBM-follower. Moreover, Algol represented the leading edge of the state-of- the-art and was ennobled by its academic and mostly European origin. 
Semiconductor license ${ }^{64}$. SGS revealed a far-seeing initiative that grew over the years independently from Olivetti's up and down: it is now-days well alive with the new name ST-Microelectronics and with the partnership of the Thompson French industry.

During the early sixties, forty Elea 9003 and seventy 6001 were delivered, that represented about a 20-30\% share of the domestic market; a result that could appear rather satisfactory, also because the Italian government never supported Olivetti with benefits - like preference in procurements, protectionism, assignment of strategic projects - that were common practice abroad in backing of the 'national champions' of the computer industry ${ }^{65}$. Moreover, DEO cash-flow heavily suffered - under the pressure of IBM's commercial policy - the practice of renting instead of selling computers. Looking at the future, the most serious drawback appeared when considering that the domestic market was far from reaching the critical width that the computer business necessitated in order to get a profitable return on investment; after all, it was the time of IBM 1401, the first computer to sell over 10,000 worldwide ${ }^{66}$. On the other hand, the powerful multinational structure of Olivetti was strictly bound to the traditional mechanical products and was then unable - as well as reluctant! - to engage the extraneous and completely different business of computers. Roberto Olivetti and Tchou sought to escape national confinement but their effort to gather abroad some industrial and/or commercial partner revealed as fruitless ${ }^{67}$.

We owe also mention that Adriano, in 1959, audaciously embarked in taking control of Underwood, an American industry whose production of office equipment fairly matched Olivetti's activities. It was the key to enter the huge and wealthy market of the States and the acquisition of a prestigious American firm by an Italian one caused sensation at the stock exchange; on the occasion, the Olivetti Corporation of America was established and the brand modified into Olivetti-Underwood.

The successful strategic move really strengthened Olivetti's leadership in the international market but the business was soon revealed as less advantageous than expected: not only the stock acquisition price was overestimated but Underwood's works at Hartford (Connecticut) appeared obsolete to the point of requiring heavy investments for restructuring. Due to Olivetti's poor financial capacity, investments implied loans from banks and the growth of indebtedness became a critical and risky concern.

Such was the overall picture when Adriano Olivetti, on February 1960, suddenly died of heart attack; the firm was completely unprepared to face such a disaster and the members of Olivetti family - the majority shareholders - decided to commit management to some extraneous personality. The electronics at Olivetti had lost its

${ }^{64}$ Worthwhile mentioning that Federico Faggin began his career at SGS. He was then hired by Fairchild and later on joined Intel, where in 1971, together with Marcian (Ted) Hoff, he built the first microprocessor, the celebrated Intel 4004.

${ }^{65}$ The notion of 'national champion' is borrowed from Chandler's essay [40].

${ }^{66}$ Because of the confinement within domestic borders, Elea computers remained almost unknown abroad. This also accounts for the recurrent lack of consideration by foreign historians.

${ }^{67}$ Similar attempts by Beltrami and Dino Olivetti had the same negative outcome. As far as the computer industry is concerned, European countries repeatedly exhibited over the years their inability to cooperate and the venture of Unidata is paradigmatic: it was established in 1972 as a transnational joint venture between Cii (France), Siemens (West Germany) and Philips (Nederland). Unidata mission consisted in a strong reaction against the supremacy of the Americans but reciprocal jealousy and mistrust of the partners caused its vanishing within a couple of years. 
authoritative tutelary deity and the supporters of the mechanical tradition, who prevailed at any level of the hierarchy, felt free to rumour against LRE and Deo that they measured only on the base of poor financial performance.

It was not enough: on November 1961, even Mario Tchou - aged only thirty seven - perished in a car crash, thus leaving Roberto Olivetti the sole defender of electronics ${ }^{68}$.

The final scene matured between 1963 and 1964 when the economy entered a worldwide recessive cycle that inevitably affected also the market of office equipment. Olivetti's finance definitely exhausted and the president Bruno Visentini - a distinguished economist - in order to avoid catastrophic bankruptcy, urged for an 'intervention group' of private banks and industries; the group acquired control of the stock - thus reducing to almost nothing the share owned by the Olivetti family - and guaranteed against default but firmly stated dismissal of the electronic division as a preliminary issue ${ }^{69}$. It was argued that - letting aside the excellence in technology investments required to successfully run the computer market overwhelmed the capabilities of every Italian industry; electronics represented after all only a tiny fraction of Olivetti's overall business that included about thirty affiliate companies abroad, twenty factories and fifty five thousand employees.

Just in that moment, General Electric was seeking for opportunities in order to widen its computer business in Europe; Olivetti's DEO in Italy and Bull in France that too was facing a financial crisis - appeared the most viable chances and GE took advantage from both.

Between 1964 and 1965 DEO was then sold to the Americans ${ }^{70}$. This marked not only the defeat of an admirable adventure, but also the definitive technological and commercial subduedness of Italy in the domain of computers. It is interesting enough that the government completely failed to appreciate the damage of losing such a unique and strategic asset, while in France the delivery of Bull to foreign hands was felt as a wound to national pride, at the point that President Charles De Gaulle reacted launching the celebrated Plan Calcul. ${ }^{71}$

In the meantime a gratifying surprise matured thanks to Pier Giorgio Perotto, an engineer who was with Tchou's team since 1957. Perotto's personality resulted incompatible with the GE representatives so that - together with his assistants Giovanni De Sandre and Gastone Garziera - he didn't quit Olivetti. In fair agreement with Roberto Olivetti and working with extremely poor resources, he was able to work out a small desktop electronic computer; not a toy but instead a professional tool at any rate, programmable by means of an essential but effective language. The Olivetti Programma 101 personal computer was born and when it was exhibited in New York

${ }^{68} \mathrm{He}$ was elected among the top managers but almost deprived of autonomous initiative. Beltrami - the DEO managing director - and Sacerdoti - who succeeded as responsible of the research laboratory - loyally assisted him but they were both in an even worst position.

${ }^{69}$ Ref. [51].

70 To be precise, the OGE (Olivetti-General Electric) company was established (75\% GE and $25 \%$ Olivetti) that became GEISI (General Electric Information Systems Italy) when GE very soon acquired 100\%. Later on (1970) Honeywell replaced General Electric and GEISI became HISI (Honeywell Information Systems Italy).

${ }^{71}$ Ref. [47], [48]. 
at the 1965 Bema Show the success was astonishing, almost obscuring the traditional mechanical products. Over the years, 44,000 machines were shipped worldwide, many of them in the United States with the Olivetti-Underwood brand (the NASA space agency was among the first customers and bought sixty) $)^{72}$.

The commercial success of the Programma 101 (P 101 for short) shocked the supporters of the mechanical technology: little by little they accepted the new course of Olivetti towards the so called 'light' electronics ${ }^{73}$. Worthwhile mentioning that the $\mathrm{P}$ 101 incorporated an I/O original feature that used removable and reusable magnetic floppy-cards as the medium for storing programs and data. Hewlett-Packard later cloned that feature in its HP 9100 model and paid to Olivetti a royalty of about one million dollars.

Olivetti's withdrawal from 'big' electronics keeps attracting the attention of Italian historians who unanimously complain about that unfortunate happening ${ }^{74}$.

Assuming a complementary point of view, it has been remarked that the LRE-DEO experience was not scratched out by General Electric but rather merged into a multinational enterprise with new criteria to handle the business ${ }^{75}$. As a matter of fact - and even if some discontinuity occurred as in the case of the already mentioned Elea 9004 project - the Italian managers, human resources, factory and research laboratory were kept almost untouched, and even increased, by General Electric ${ }^{76}$.

The story of Elea 4001 is meaningful enough. This medium-sized computer was launched by Olivetti in 1964 and represented the most valuable and ready-to-market asset that DEO brought as a dowry; with a minimum reshaping in order to fit the GE series of computers, Elea 4001 was marketed as GE 115 and sold over 4,000, being particularly successful in the United States. It was the first time that a computer entirely designed and produced in Italy massively reached foreign markets; a result that - according to previous discussion - Olivetti could have hardly achieved.

Over the years, many other 'Italian' computers went through the word under the General Electric - and later Honeywell - brand that left hidden their origin; among them, in the early Seventieth, the Level 2 model of the Honeywell Series 60, was even licensed to the Japanese Hitachi.

72 Ref. [50]. A key factor of the P 101 success was that, quite differently from huge computer systems, it perfectly matched the practices of office equipment sale forces: the P 101 could be sold piece by piece (at the price of $\$ 3,200$ ) and was extremely easy to use and to maintain.

73 Later on, electronics arrived to affect the same traditional office equipment: the Auditronic 770 accounting machine (1969), the Logos 250 calculator (1970) and the ET 101 typewriter (1978) represented the first electronic products of their category.

74 Ref. [52], [53].

75 Ref. [54]. To give but an example, 'product planning' methodology was introduced by the Americans and represented a novelty for the Italian management culture.

76 The computer factory remained at Caluso, near Ivrea, and the research centre was kept at Pregnana (Milano) under the guidance of Franco Filippazzi. 


\section{APPENDIX: Where to Meet Computer Relics throughout Italy}

\section{MILANO: CRC 102-A Central Processing Unit (Politecnico di Milano).}

PISA: CEP, CINAC (CPU only), ELEA 6001, Bull Gamma 3, Tau2-Taumus and many more (Museo degli strumenti di calcolo); Documents at the Archivio Generale di Ateneo.

ROMA: ELEA 9003 (Museo delle Poste e Telecomunicazioni); Documents and INAC's mechanical calculators at the Archivio Storico IAC.

BIBBIENA (Arezzo): ELEA 9003, functioning! (Istituto Tecnico 'E. Fermi').

IVREA (Torino): Olivetti P101 and many other Olivetti products (Museo-Laboratorio Tecnologic@mente); Documents at the Archivio Storico Olivetti.

\section{References}

[1] De Marco, G., Mainetto, G., Pisani, S., Savino, P.: The Early Computers of Italy. IEEE Annals of the History of Computing 21(4), 28-36 (1999)

[2] Bonfanti, C.: Mezzo secolo di futuro. - L'informatica italiana compie cinquant'anni. Mondo Digitale (3), 48-68 (2004)

[3] Cull, P.: Caianiello and Neural Nets. In: Termini, S. (ed.) Imagination and Rigor - Essays on Eduardo R. Caianiello's Scientific Heritage, pp. 47-61. Springer (2006)

[4] Fadini, B.: Calcolo analogico ed ibrido - L'esperienza dell'Università di Napoli. In: Convegno Internazionale Sulla Storia e Preistoria del Calcolo Automatico e Dell'informatica, pp. 127-144. AICA, Milano (1991)

[5] Contin, G., Patergnani, G., Piva, F.: Calcolatore elettronico per uso didattico e scientifico. In: Abstract from the Proceedings of the VIII Rassgna Internazionale Elettronica e Nucleare, Roma (1961)

[6] Böhm, C.: Calculatrices Digitales - Du déchiffrage de formules logico-mathématiques par la machine même dans la conception du programme. Annali di Matematica Pura ed Applicata (1954)

[7] Böhm, C., Jacopini, G.: Flow Diagrams, Turing Machines and Languages with Only Two Formation Rules. Comm. of the ACM 9(3), 366-371 (1966)

[8] Croce, B.: Logica come scienza del concetto puro, 7th edn. Laterza (1958); 1st edn. (1905)

[9] Carassa, F.: La nascita dell'elettronica e delle telecomunicazioni: Vecchiacchi e i rapporti con l'industria. In: Il Politecnico di Milano Nella Storia Italiana, vol. II, pp. 499-506. Laterza (1964)

[10] Dadda, L.: Il centro di calcoli numerici e l'introduzione delle discipline informatiche al Politecnico di Milano. In: Convegno Internazionale Sulla Storia e Preistoria del Calcolo Automatico e Dell'informatica, pp. 7-44. AICA, Milano (1991)

[11] Dadda, L.: Ricordi di un informatico. In: Cuzzer, A. (ed.) La cultura Informatica in Italia - Riflessioni e Testimonianze Sulle Origini, 1950-1970, pp. 67-106. Bollati Boringhieri, Torino (1993)

[12] Nastasi, P.: Picone, il calcolo automatico e Finac: una storia lunga 30 anni. Pristem/Storia (12-13), 121-171 (2006)

[13] Guerraggio, A., Mattaliano, M., Nastasi, P.: La "lunga marcia" di Mauro Picone (18851977). Università Bocconi, Milano (2010)

[14] de Finetti, B.: Macchine "che pensano" (e che fanno pensare). Tecnica ed Organizzazione (3-4), 182-215 (1953) 
[15] de Finetti, B., Kitz, N., Rodinò, G.: Symposium on automatic digital computation - Nat. Phys. Laboratory - Teddington (Londra). La Ricerca Scientifica (7), 1248-1259 (1953) (the article is in Italian)

[16] Goldstine, H.H.: The Computer from Pascal to von Neumann. Princeton University Press (1972)

[17] Bonfanti, C.: L'affare Finac tra Manchester e Roma (1953-1955) ed alcuni documenti inediti ad esso relativi. In: Atti del Congresso Annuale AICA - Palermo, pp. 35-64. AICA, Milano (1994)

[18] Ercoli, P.: Otto anni di attività del calcolatore dell'Istituto Nazionale per le Applicazioni del Calcolo. In: Atti del I ${ }^{\circ}$ Congresso Annuale AICA, Bologna (1963)

[19] Ercoli, P.: Systems and Programming Aspects of the Computer INAC. Calcolo (4), 441470 (1966)

[20] Vittorelli, V.: The Olivetti-INAC Computer. Calcolo (4), 481-491 (1966)

[21] Ercoli, P.: From CINAC to FINAC. In: Convegno Internazionale Sulla Storia e Preistoria del Calcolo Automatico e dell'Informatica, Siena, Settembre 10-12, pp. 57-68. AICA, Milano (1991)

[22] Numerico, T., Freguglia, R.: Le ricerche in informatica. In: Simili, R., Paoloni, G. (eds.) Per una Storia del Consiglio Nazionale Delle Ricerche, Laterza, vol. II, pp. 408-440 (2001)

[23] Rossi, B.: Cosmic Rays. McGraw-Hill (1964)

[24] Auerbach, I.L.: European Electronic Data Processing - A Report on the Industry and the State-of-the-Art. In: Proc. of the IRE, pp. 330-348 (January 1961)

[25] Denoth, F.: CEP (Calcolatrice Elettronica Pisana. Dal CSCE all'IEI. In: Convegno Internazionale Sulla Storia e Preistoria del Calcolo Automatico e Dell'informatica, Siena, Settembre 10-12, pp. 105-115. AICA, Milano (1991)

[26] Andronico, A.: Alfonso Caracciolo di Forino: attività scientifica a Pisa. In: Vanneschi, M. (ed.) La CEP: Storia, Scienza e Umanità Dell'avventura Informatica Pisana, pp. 6693. Felici Editore, Pisa (2009)

[27] Vanneschi, M.: L'opera scientifica di Giovan Battista Gerace. In: Vanneschi, M. (ed.) La CEP: Storia, Scienza e Umanità Dell'avventura Informatica Pisana, pp. 94-105. Felici Editore, Pisa (2009)

[28] Faedo, A.: L'ambiente pisano e l'istituzione del primo corso di laurea in Scienza dell'Informazione. In: Convegno Internazionale Sulla Storia e Preistoria del Calcolo $\mathrm{Au}-$ tomatico e Dell'informatica, Siena, Settembre 10-12, pp. 119-125. AICA, Milano (1991)

[29] Maestrini, P.: Le tecnologie digitali al tempo della CEP. In: Vanneschi, M. (ed.) La CEP: Storia, Scienza e Umanità Dell'avventura Informatica Pisana, pp. 66-93. Felici Editore, Pisa (2009)

[30] Blackman, N.M.: The state of Digital Computer Technology in Europe. Comm. of the ACM 4, 256-265 (1961)

[31] Kerf, J.L.F.: A survey of the New West-European Digital Computers. Computers and Automation (12), 27-38 (1963)

[32] Mancino, O.G., Sprugnoli, R.: CEP: la Calcolatrice Elettronica Pisana - Scenario, storia, realizzazione, eredità. Pisa University Press (2011)

[33] Caizzi, B.: Camillo e Adriano Olivetti. U.T.E.T., Torino (1962)

[34] Occhetto, V.: Adriano Olivetti industriale e utopista. Cossavella Editore, Ivrea (2000)

[35] Renzi, E.: Comunità concreta: le opere e il pensiero di Adriano Olivetti. Guida Editore, Napoli (2008)

[36] Dadda, L.: Il settore dei calcolatori. In: La Ricerca Industriale per L'Italia di Domain, pp. 549-571. FAST, Milano (1967) 
[37] Weik M.A.: A Survey of Domestic Electronic Digital Computer Systems. U.S. Department of Commerce - Office of Technical Services (December 1955)

[38] Bordòli, P.: Olivetti-Bull (1949-1964) - Una tappa importante per l'informatica italiana. Doctoral thesis at the University of Modena and Reggio Emilia (2012)

[39] Sacerdoti, G.: Il calcolatore Olivetti Elea 9003. In: Contributi All'automazione Aziendale, pp. 3-13. Olivetti S.p.A (1959)

[40] Chandler, A.D.: Inventing the Electronic Century. The Free Press (2001)

[41] Filippazzi, F., Sacerdoti, G.: Progetto ELEA: il primo computer made in Italy. In: Convegno Internazionale Sulla Storia e Preistoria del Calcolo Automatico e Dell'informatica, Siena, Settembre 10-12, pp. 187-203. AICA, Milano (1991)

[42] De Witt, G.: Le fabbriche e il mondo. L'Olivetti industriale nella competizione globale (1950-1990). Franco Angeli, Milano (2005)

[43] Piol, E.: Il sogno di un'impresa. Dall'Olivetti al venture capital: una vita nell'Information Technology. Edizioni de Il Sole 24 Ore, Milano (2004)

[44] Beltrami, O.: Sul ponte di comando: dalla Marina Militare all'Olivetti. Mursia, Milano (2004)

[45] Bellisario, M.: Donna e top manager: la mia storia. Rizzoli, Milano (1987)

[46] Silmo, G.: L'Olivetti e l'elettronica: una storia esemplare. Tipografia Giannotti Editore (2010)

[47] Brulé, J.-P.: L'Informatique malade de l'État - Du Plan calcul à Bull nationalisée. Les Belles Lettres (1993)

[48] Mounier-Kuhn, P.-E.: National Policies Towards Informatics in France (1945-1975). In: Convegno internazionale Sulla Storia e Preistoria del Calcolo Automatico e Dell'informatica, Siena, Settembre 10-12, pp. 353-369. AICA, Milano (1991)

[49] Rao, G.: La sfida al futuro di Adriano e Roberto Olivetti. MéLanges de l'École Française de Rome, Tome 115, 643-678 (2003)

[50] Perotto, P.G.: Programma 101 - L'invenzione del Personal Computer: una storia appassionante mai raccontata. Sperling \& Kupfer, Milano (1995)

[51] Bricco, P.: Olivetti, prima e dopo Adriano: industria, cultura, estetica. L'ancora, Napoli (2005)

[52] Soria, L.: Informatica: un'occasione perduta. Einaudi, Torino (1979)

[53] Gallino, L.: La scomparsa dell'Italia industriale. Einaudi, Torino (2003)

[54] Bonfanti, C.: L'industria del computer in Italia - Appunti per una storia. In: Luccio. F. (ed.) L'informatica: lo Sviluppo Economico, Tecnologico e Scientifico in Italia, Italia, pp. 75-118. Edifir - Edizioni Firenze (2007)

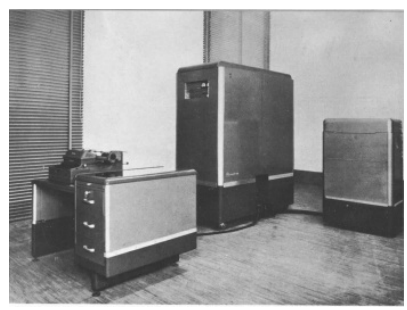

Fig. 2.1. CRC 102-A
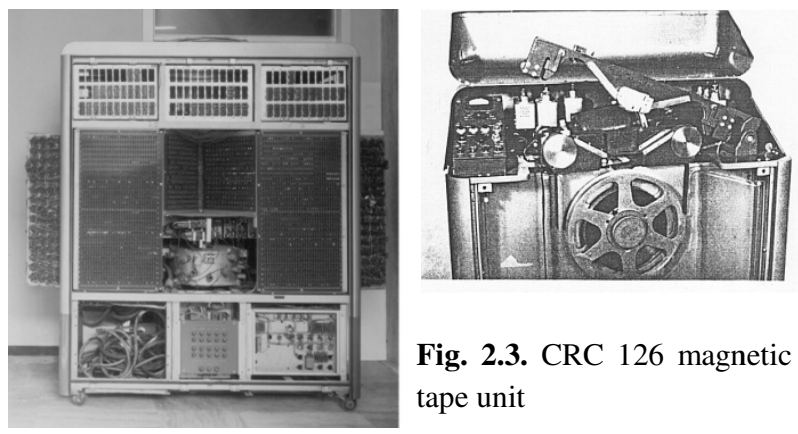

Fig. 2.3. CRC 126 magnetic tape unit

Fig. 2.2. CRC 102-A (CPU)

still preserved at the

Polytechnic of Milano 


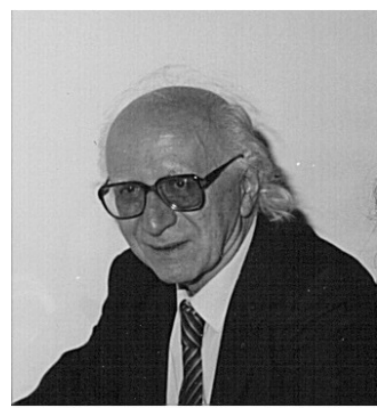

Fig. 2.4. Luigi Dadda (1991)

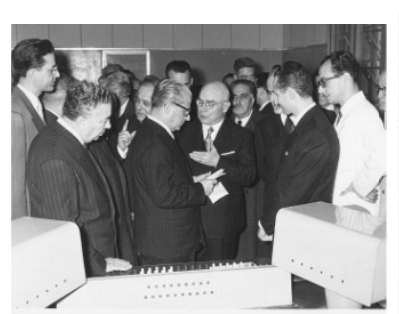

Fig. 3.3. Official inauguration of the FINAC (1955): President Giovanni Gronchi with Picone (centre), Enzo Apàro (on the left), Paolo Ercoli (on the right) and Corrado Böhm (second from right

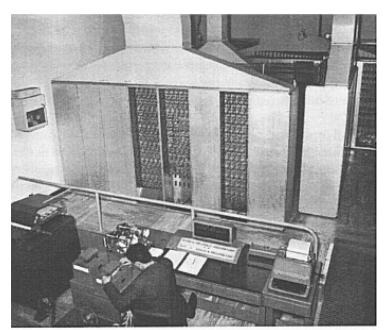

Fig. 4.2. Partial view of the CEP

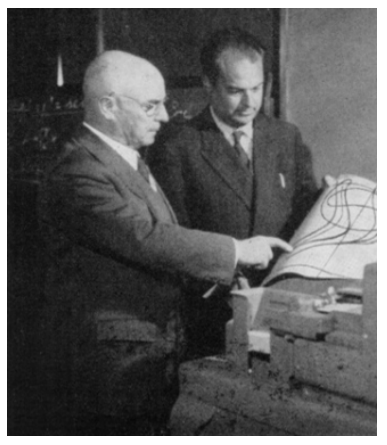

Fig. 3.1. Mauro Picone (left) with Bruno de Finetti (1952)

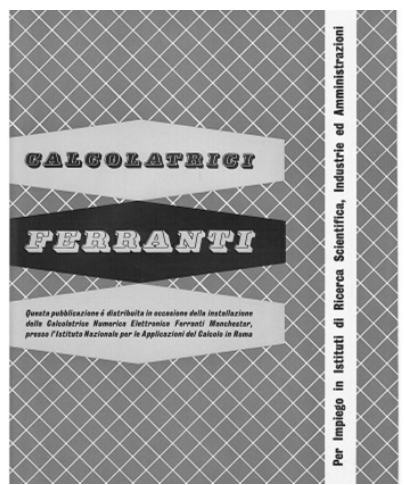

Fig. 3.4. Title-page of a Ferranti's advertising brochure (1955, in Italian!)

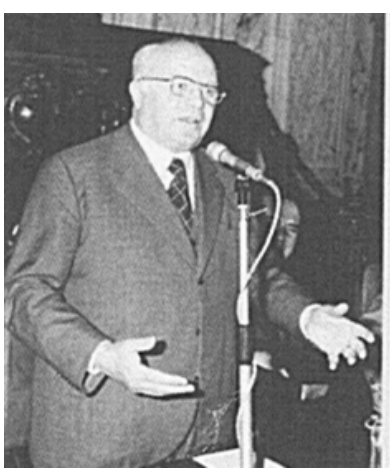

Fig. 4.3. Alessandro Faedo (about 1964)

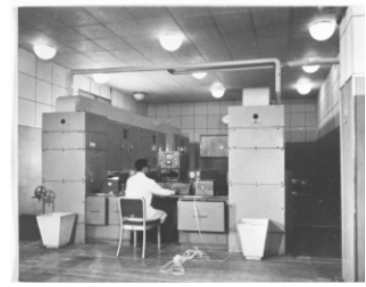

Fig. 3.2. FINAC (Ferranti Mark I*)

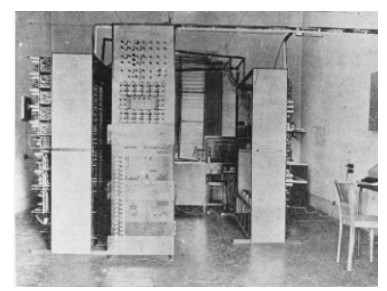

Fig. 4.1. CSCE 'Reduced Machine'

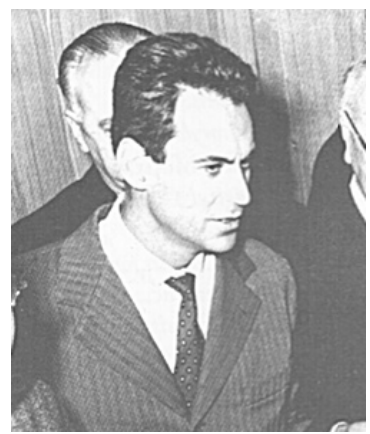

Fig. 4.4. Giovanni Battista Gerace (1960) 


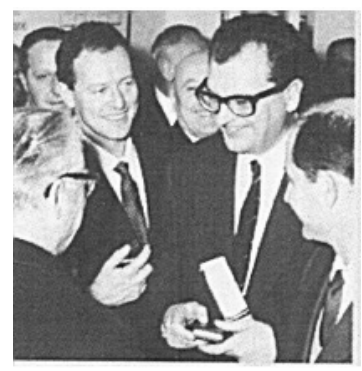

Fig. 4.5. Marcello Conversi (centre left) and Giuseppe Cecchini (centre right) (1960)

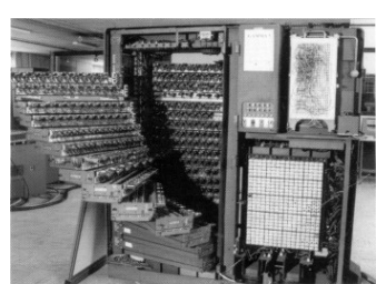

Fig. 5.2. Bull Gamma 3

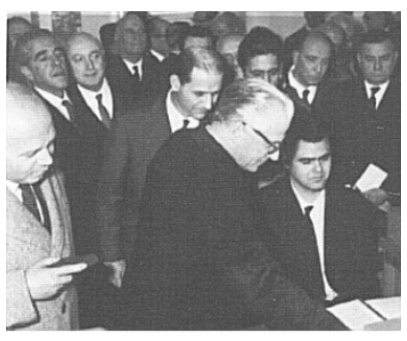

Fig. 4.6. Official inauguration of the CEP (1960): Alessando Faedo on the extreme left side, President Gronchi at centre and Alfonso Caracciolo at his left (1960)

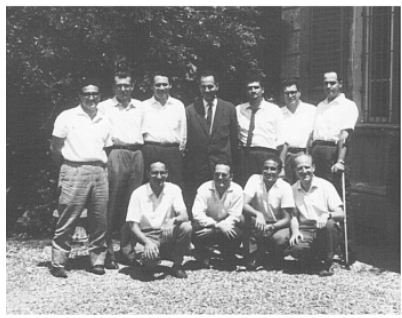

Fig. 5.3. The 'Barbaricìna guys' (1956) Standing from left: G. Calogero, F. Filippazzi, M. Tchou, R. Galletti, P. Grossi, S. Sibani, G. Sacerdoti. Kneeling from left: L. Borriello, S. Fubini, O. Guarracino, G. Raffo. (On the occasion, M. Friedman was away.)

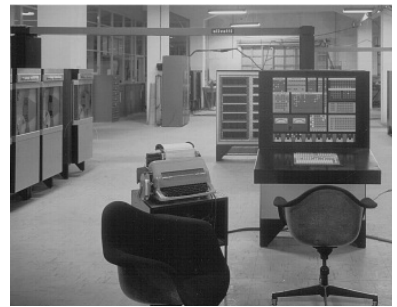

Fig. 5.5. ELEA 9003 (Industrial design by Ettore Sottsass Jr)

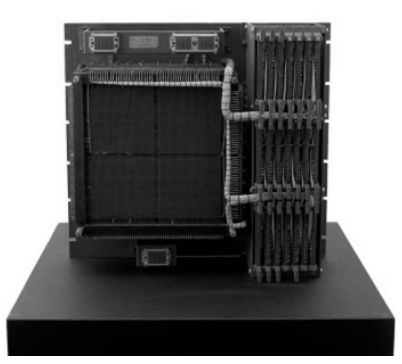

Fig. 5.6. ELEA 9003: a 10 Kchar core memory module

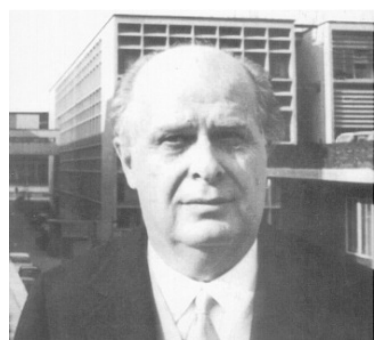

Fig. 5.1. Adriano Olivetti. (About 1958; in the background some Olivetti's buildings in Ivrea)

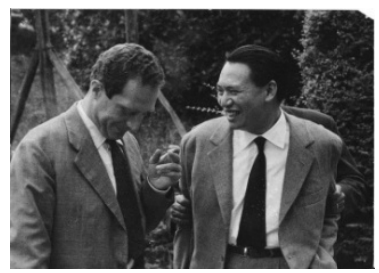

Fig. 5.4. Roberto Olivetti with Mario Tchou (about 1958)

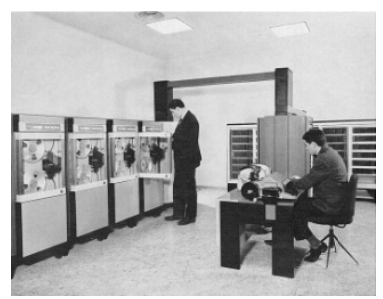

Fig. 5.7. ELEA 6001 


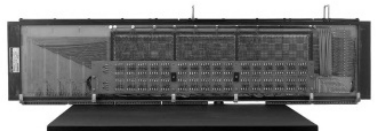

Fig. 5.8. ELEA 6001: microprogrammed ROM
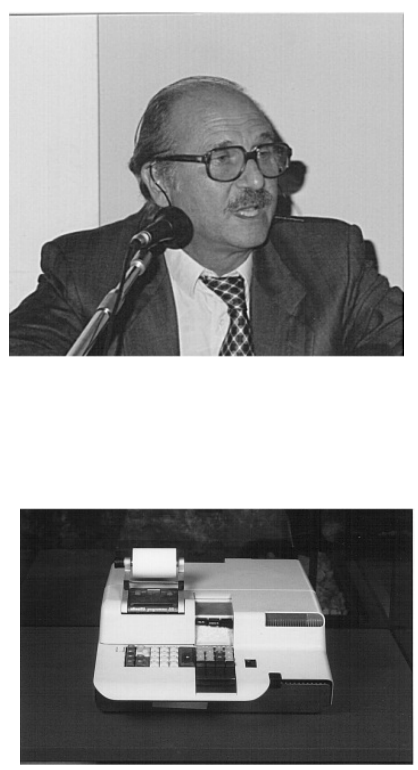

Fig. 5.12. Olivetti $P 101$ desk-top computer (industrial design by Mario Bellini)

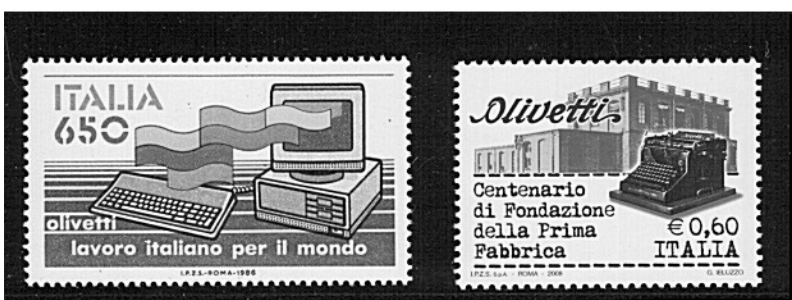

Fig. 5.12. Italian stamps: Olivetti M 24 Personal Computer (issued 1986) and Olivetti's Centenary (issued 2008)

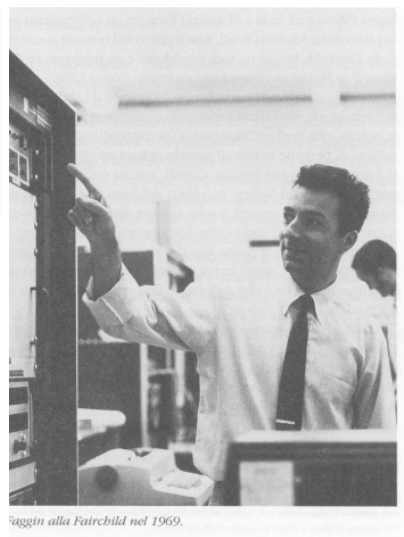

Fig. 5.10. Federico Faggin at Intel (1969)

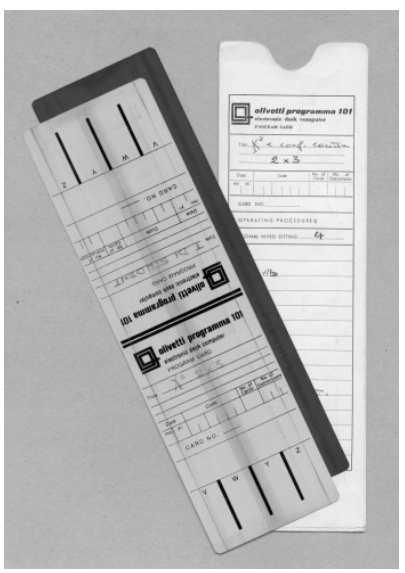

Fig. 5.11. $P 101$ floppy card (the black reverse is the magnetic-sensitive side) 